\title{
The Economics of Residential Solar and Battery Storage: Analyzing the Impact of the Joint IOU Proposal for Net Metering 3.0 in California
}

\author{
Candace E. Ybarra, Prashanth U. Nyer*, John B. Broughton, Thomas A. Turk \\ Argyros School of Business \& Economics, Chapman University, Orange, CA, USA \\ Email: cybarra@chapman.edu, ^nyer@chapman.edu,broughto@chapman.edu,turk@chapman.edu
}

How to cite this paper: Ybarra, C. E., Nyer, P. U., Broughton, J. B., \& Turk, T. A. (2021). The Economics of Residential Solar and Battery Storage: Analyzing the Impact of the Joint IOU Proposal for Net Metering 3.0 in California. Low Carbon Economy, 12, 137-150.

https://doi.org/10.4236/lce.2021.124007

Received: September 22, 2021

Accepted: October 30, 2021

Published: November 2, 2021

Copyright $\odot 2021$ by author(s) and Scientific Research Publishing Inc. This work is licensed under the Creative Commons Attribution International License (CC BY 4.0).

http://creativecommons.org/licenses/by/4.0/

\begin{abstract}
The California Public Utilities Commission (CPUC) is currently deciding on the structure of the next net metering program, which will determine how customers who install solar panels (and battery storage) under this new program will be compensated for excess energy that they export to the grid, and the additional fees that these solar customers will have to pay. The major investor-owned utility (IOU) companies in the state and some legislators have argued that the current net metering programs are far too generous to the customers and that they create an inequity by favoring the wealthy and causing a cost shift to the poorer non-solar customers. The IOUs have jointly proposed a set of regulations to the CPUC. In this paper, we examine the financial implications to residential customers who go solar under the new net metering program if the joint IOU proposal were to be adopted. We examine the case of a hypothetical southern California home that consumes the average amount of electricity (for that region) and estimate its electricity bills for various load profiles, assuming no solar or battery storage, with solar alone, and with solar and battery storage. For the two latter scenarios, we determine the ideal system configuration that will maximize the customer's financial returns. In all cases, we determine that the joint IOU proposal for net metering will make residential solar panel and battery storage installations financially unattractive even in the best-case scenarios. In short, if the CPUC adopts the joint IOU proposal then residential solar installations in the state would likely come to an abrupt stop. We also analyze the economics of going offgrid (where a customer completely cuts himself off from the electrical grid) and find that it does not make sense for customers to go off-grid without being willing to cut consumption or make other compromises.
\end{abstract}

\section{Keywords}

Solar Panels, Battery, Net Metering, NEM, Off Grid 


\section{Introduction}

This paper examines the financial implications to residential homeowners who may install solar panels or solar panels combined with battery storage in the near future, under the regulations proposed by the three major electric utility companies in California. The California Public Utilities Commission (CPUC) (2021), a state government agency tasked with regulating privately owned electric, natural gas and other utility companies, is currently considering potential changes to the state's net energy metering (also known as net metering) policies. Net metering refers to the policies and rules that determine how customers who generate their own electrical energy (most commonly using solar panel arrays) are credited for any excess energy exported to the electrical grid, and how they are charged for energy imported from the grid. The original net metering program (NEM 1.0) approved in 2013, did not force customers into time-of-use rate plans, and solar customers under NEM 1.0 were grandfathered under the then prevailing rules for 20 years. A customer who installed a solar panel array under NEM 1.0 could stay on a tiered rate plan where they paid the same rate for electricity regardless of the time of day. Any excess solar generated electricity that the customer exported to the grid was compensated for at the retail rate. In other words, one kilowatt hour $\left(\mathrm{kWh}^{1}\right)$ of electricity exported to the grid was compensated for at the same rate as one $\mathrm{kWh}$ of electricity purchased from the grid at some other time. Thus, under NEM 1.0 solar customers (i.e., customers with solar panel arrays) could treat the electrical grid as an infinitely large, and $100 \%$ efficient, free battery storage facility. Despite solar panels being more expensive in the early years, customers found it financially attractive to go solar under NEM 1.0 (Nyer, Broughton, \& Ybarra, 2019). The NEM 1.0 program came to an end in 2016-2017, with the exact date varying by the investor-owned utility company $\left(\mathrm{IOU}^{2}\right)$ and was replaced by the current net metering program (NEM 2.0).

Solar customers under NEM 2.0 are still able to sell excess energy produced by their solar panel arrays to their IOU but are forced into time-of-use (TOU) rate plans where the rates are typically much lower during peak sunlight hours, and significantly higher during the peak demand hours in the evening. For example, SCE currently charges customers on their TOU 4 - 9 rate plan $\$ 0.27$ per kWh between 8:00 AM and 4:00 PM, and \$0.47 per kWh between 4:00 PM and 9:00 PM. Thus, under NEM 2.0, a kWh of electricity exported to the grid at 1:00 PM would earn a credit of $\$ 0.27$, while the customer would pay SCE $\$ 0.47$ for a $\mathrm{kWh}$ purchased at 7:00 PM. Additionally, NEM 2.0 imposed certain additional non-bypassable charges (NBC) of approximately $\$ 0.02$ per $\mathrm{kWh}$, that NEM 1.0 customers are not subject to. NEM 2.0 customers also had to pay a one-time interconnect fee ranging between $\$ 75$ to $\$ 150$ (depending on the IOU). Customers who go solar under NEM 2.0 will be grandfathered into that program for 20 years. While NEM 2.0 is not as financially attractive to customers as NEM 1.0 was, it ${ }^{1} \mathrm{~A} \mathrm{kWh}$ is the amount of energy consumed by a 1000-watt appliance in one hour. ${ }^{2}$ California has three major IOUs: Pacific Gas \& Electric (PG\&E), Southern California Edison (SCE) and San Diego Gas \& Electric (SDGE). 
still provides a good return on investment to customers (Nyer, Ybarra, \& Broughton, 2019). Both NEM 1.0 and NEM 2.0 have been very popular with customers in California, with 2342 megawatts of new solar generating capacity being added in 2013-2016 by 428,504 residential customers, and an additional 3149 megawatts of capacity added by 521,378 residential customers in 2017-2020 (see Ybarra, Broughton \& Nyer, 2021 for an analysis of the trends in residential solar installations in the state). However, NEM 2.0 is soon coming to an end and will be replaced by NEM 3.0. The details of NEM 3.0, which is expected to go into effect in 2022, are being determined by the CPUC.

\section{Criticisms of NEM 1.0 and 2.0}

The IOUs and some legislators who wish to scale back California's net metering program have argued that net metering programs are far too generous to solar customers. They contend that residential solar installations are mostly done by wealthier people who then pay little if anything for electricity, and this in turn causes less well-off, non-solar customers to shoulder most of the cost of maintaining and operating the electrical grid and generation infrastructure resulting in non-solar customers paying higher electricity rates. This is a valid argument, and Ybarra, Broughton, \& Nyer (2021) found evidence to support the claim that residential solar panel installations were being done mostly by wealthier customers. Opponents of net metering include Ms. Lorena Gonzales, Assemblyperson from San Diego, who is also the chair of the influential appropriations committee. She introduced assembly bill AB 1139, with the support of the Coalition of Utility Employees (a group closely aligned with the IOUs) which called for all past grandfathering for customers who had previously gone solar under NEM 1.0 and NEM 2.0 to be limited to just 5 years, rather than the 20 years that they were promised. AB 1139 was defeated in June 2021, but similar legislation is likely to come up for a vote in future years.

\section{Joint IOU Proposal}

In March 2021, the three IOUs in the state submitted a document to the CPUC (CPUC, 2021) with suggestions on how NEM 3.0 should be structured. In brief, these proposals include:

1) Assigning all future solar customers (those going solar under NEM 3.0 and afterwards) to solar specific rate plans (for SCE customers this will be their existing TOU D Prime rate), and forcing new solar customers into NEM 3.0 even before NEM 3.0 has been fully finalized,

2) Setting the export compensation rate (what solar customers are credited for sending excess energy to the grid) to the IOU's avoided cost, rather than to the retail rate, and limiting the amount of energy that qualifies for export compensation (we explain this below),

3) Imposing substantial additional monthly charges on solar customers.

The export compensation rate and the additional monthly charges being pro- 
posed vary by the IOU. For SCE, the export compensation rate during the peak sunlight hours (when most of the solar energy is generated) would be only $\$ 0.07$ per $\mathrm{kWh}$. Compare this with the retail rate of $\$ 0.27$ per $\mathrm{kWh}$ that customers on NEM 2.0 receive for energy that they export to the grid at the same time. However, it is unlikely that solar customers will be paid even $\$ 0.07$ per $\mathrm{kWh}$ for the excess energy they generate. The joint IOU proposal states "Customers will pay the retail rate for all delivered energy. For each billing cycle (usually monthly), a customer's exported energy will be priced at the applicable export compensation rate depending on the TOU period, up to the amount that is delivered to the customer in that same TOU period. Any remaining exported energy... will be paid at the monthly net surplus compensation rate". What this means is that if in a billing cycle (a month) an SCE customer sends $300 \mathrm{kWh}$ of energy to the grid during the 8:00 AM to 4:00 PM time slot, and imported $50 \mathrm{kWh}$ of energy from the grid during the same time slot, the customer would pay $\$ 0.27$ for each of the $50 \mathrm{kWh}$ that were purchased, get the export compensation rate of $\$ 0.07$ for 50 $\mathrm{kWh}$ of exports, and be credited with merely $\$ 0.03$ per $\mathrm{kWh}$ for the remaining $250 \mathrm{kWh}$ of exports. This would make it financially unattractive for customers to export excess energy to the grid, and may encourage them to use battery storage to save the excess energy for use when the panels are not producing. IOUs have a vested interest in encouraging customers to install solar-coupled battery storage since that reduces the peak demand experienced by the grid. However, if a large number of customers adopt solar-coupled battery storage, that will result in lower revenues for the IOUs.

This has prompted the IOUs to propose two additional charges for customers going solar under NEM 3.0. The first of these is a flat monthly fee named 'Customer Charge', which for SCE customers would be $\$ 12.02$, but much higher for customers of PG\&E (\$20.66) and SDGE (\$24.10). The second charge, named Grid Benefits Charge would be based on the size of each customer's solar panel array in kilowatts, and would be $\$ 7.39$ per $\mathrm{kW}$ for SCE customers, $\$ 10.93$ per $\mathrm{kW}$ for PG\&E customers, and $\$ 11.09$ per $\mathrm{kW}$ for SDGE customers. Thus, a PG\&E customer with a modest $5.78 \mathrm{~kW}$ solar panel array (the average state-wide residential solar panel array size for installations in 2013-2020; data from Ybarra, Broughton, \& Nyer, 2021) would incur a Grid Benefits Charge of $\$ 63.18$ per month.

If implemented, these proposals are likely to make residential solar panel installations very unattractive to customers. IOUs have long argued that utility-scale solar panel farms (controlled by the IOUs) are more cost effective than solar panel arrays installed by the customers. While this is undoubtedly true, what this argument fails to recognize are the many benefits of distributed generation (decentralized generation, which includes residential solar panel installations). With distributed generation, energy consumption takes place at the same location where energy generation takes place, thus reducing the impact on the grid, and the necessity to incur large grid improvement expenses. Distributed 
generation usually takes advantage of existing rooftop space, thus eliminating the need for large solar farms and the accompanying environmental compromises that must be made. Distributed generation helps create many small businesses and thousands of jobs state-wide.

\section{Economics of Residential Solar with/without Battery Storage under the Joint IOU Proposal}

In this section we will determine the economic viability of residential solar panels with and without battery storage for a median sized home under the IOU proposed regulations.

\subsection{Data}

Following Broughton, Nyer, \& Ybarra (2021), we examine a hypothetical SCE residential customer in ZIP code area 92,867 who consumes $7411 \mathrm{kWh}$ of electrical energy each year (this corresponds to the average yearly electricity use per household for this ZIP code in 2018-2019 (SCE, 2021a). Using data from SCE on the timing and quantity of average residential customer electricity usage, we estimated the hourly electricity consumption for this hypothetical customer for each month of the year.

Since this hypothetical customer consumes $7411 \mathrm{kWh}$ annually, we designed an unobstructed $4.541 \mathrm{~kW}$ DC solar panel system (with a commonly used roof angle of $20^{\circ}$ ) that would generate $7411 \mathrm{kWh}$ of energy annually when installed facing south. The solar production data for this hypothetical customer was estimated using National Renewable Energy Laboratory's (NREL; a national laboratory of the U.S. Department of Energy) PVWatts web application

(https://pvwatts.nrel.gov/). The PVWatts site estimates the hourly electricity production of a solar panel installation (for each day of the year) based on the system's location, the directional orientation of the array, tilt angle and array size. In addition, PVWatts uses the solar irradiance and meteorological data for the system's location to arrive at their estimates. The data from PVWatts were corrected for daylight savings time.

With the customer's hourly electricity consumption and electricity generation data in place, it was then possible for us to determine this customer's hourly net export or import of energy. This combined with the tariff data (SCE, 2021b) made it possible for us to calculate the customer's annual electricity expenses under various scenarios.

\subsection{Load Profiles}

Not all customers have the same electricity usage pattern. People working and studying at home will have a different usage profile compared to people who are not home during the daytime on weekdays. To make our analyses more generalizable, we used the four hypothetical load profiles from Broughton, Nyer, \& Ybarra (2021). The annual electricity consumption for all four load profiles was 
set to $7411 \mathrm{kWh}$ (see Figure 1 for some of these load profiles). The four load profiles are described below (the description below and Figure 1 have been reproduced from Broughton, Nyer \& Ybarra, 2021 with permission.)

1) Adults working from home. These households typically have someone home throughout the day. As such, during the summer months air-conditioners get turned on earlier in the afternoon. Once the house is cooled, the electrical load will be relatively lower during the later evening hours.

2) Adults working outside the home with no children. These homes will typically be unoccupied during the work-day and will see a sharp increase in electricity use in the early evening hours in summer when the residents return from work.

3) Adults working from home but away from $5 \mathrm{PM}$ to $8 \mathrm{PM}$. These could be individuals who work from home and attend school or run errands in the evening. These households typically have a usage pattern similar to load profile A with the difference that the energy consumption is low between $5 \mathrm{PM}$ and $8 \mathrm{PM}$.

4) Adults working outside the home with school aged children. School aged children tend to be home for part of the summer, and when in school they tend to return home earlier than their parents. Thus, during the summer months these homes tend to see their air-conditioners turned on earlier than the homes without children (load profile B above).

Some of the simulated load profiles (for the summer months) are shown in Figure 1 (the load profile D, for working adults with school-aged children, has not been included to improve the legibility of the illustration. Load profile $\mathrm{D}$ is similar to profile B, but with a bump in electricity use when schoolchildren return home from school.) While our simulations divided the year into three

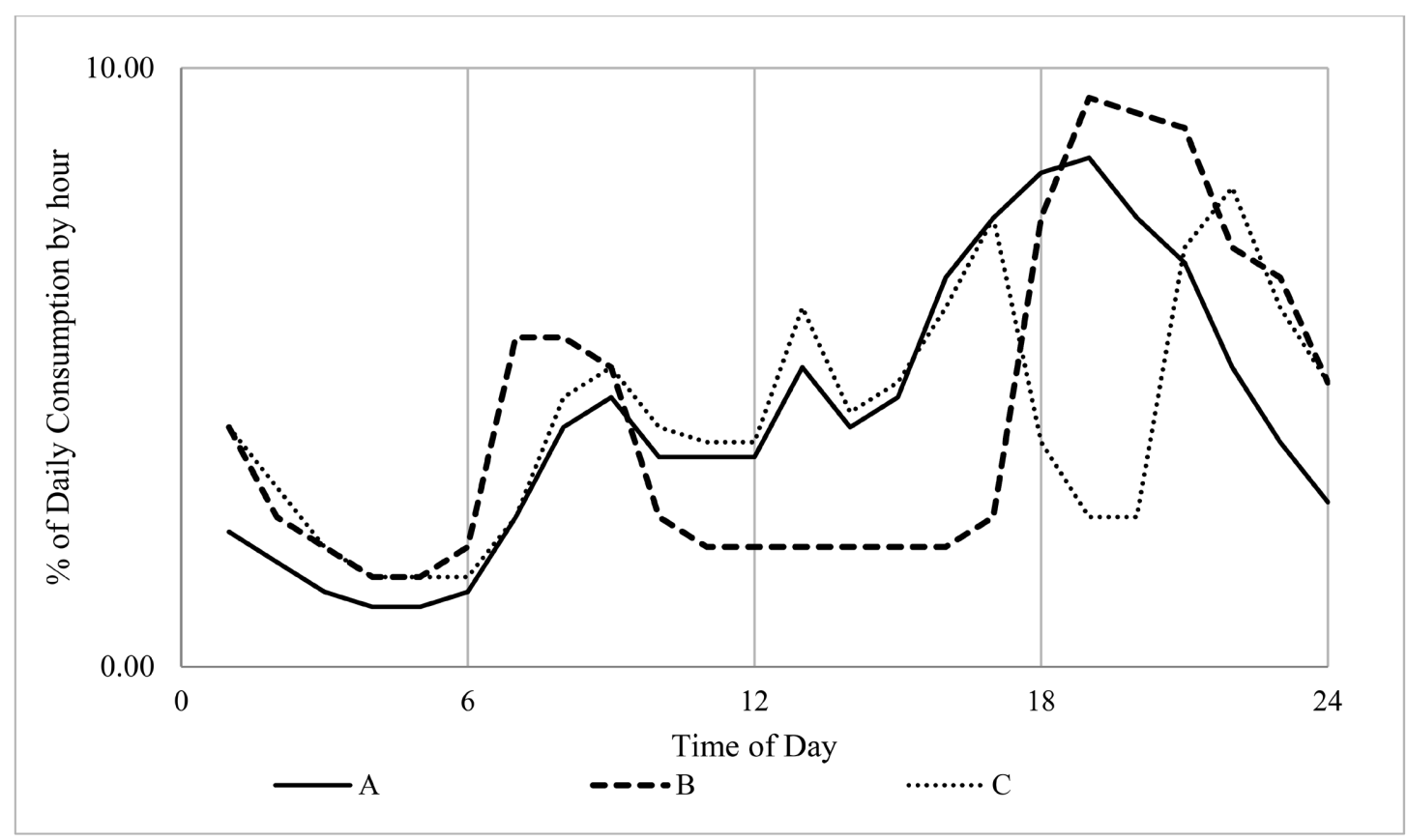

Figure 1. Load Profiles (reproduced from Broughton, Nyer and Ybarra, 2021 with permission). 
seasons (Summer, Winter and Spring/Fall), Figure 1 includes only the Summer load profiles to declutter the illustration.

\section{Findings}

\subsection{Financial Impact of Solar Panels at $100 \%$ Usage Offset under the Joint IOU Proposal}

Table 1 summarizes the annual electricity bills for the hypothetical home, with and without solar panels, under the TOU D Prime rate plan for the four load profiles (current tariffs from 2021 were used). To reduce the number of scenarios that we examine, we assume that the solar panels are installed facing south and that the array is sized to exactly match the annual electricity consumption of the household of $7411 \mathrm{kWh}$ (in other words, the usage offset is 100\%). The annual avoided electricity cost was computed for each load profile, and from that the payback period, net present value (NPV) and internal rate of return (IRR) were calculated. NPV is the discounted present value of the stream of avoided costs minus the installed cost of the solar system. Positive values of NPV indicate that the solar system creates value for the homeowner and is a good investment. The discount rate used to calculate NPV is the cost of financing the solar installation. We conducted an informal survey of solar installers and financial institutions to gauge the approximate financing cost for residential solar systems. The lowest rates by loan term were $4.49 \%$ ( 8 year), 5.49\% (12 year), and $6.49 \%$ (20 year). These rates required a FICO score of 720 or higher. In Table 1 we compute the NPV using both $4.49 \%$ and $6.49 \%$. IRR is the discount rate that would result in an NPV of exactly zero and provides a threshold financing rate. If it is possible to finance the solar system at a rate below the IRR, the NPV is positive.

In our analysis, we assumed that the solar panels would last 25 years (25 years is the typical warrantied life of solar panels.) We did not adjust for the slight degradation in the energy generation of solar panels as they age (typically a $10 \%$ reduction by the $25^{\text {th }}$ year) since this is offset by the increasing cost of electricity.

Table 1. Financial Impact of Solar Panels under proposed NEM 3.0 rules (100\% Usage Offset).

\begin{tabular}{ccccc}
\hline & \multicolumn{3}{c}{ Load Profiles } \\
\cline { 2 - 5 } & A & B & C & D \\
\hline Annual electricity charge without solar & $\$ 2251.10$ & $\$ 2239.72$ & $\$ 2021.94$ & $\$ 2236.20$ \\
Annual electricity charge with solar & $\$ 1679.90$ & $\$ 1895.39$ & $\$ 1449.32$ & $\$ 1781.15$ \\
Annual avoided electricity charge & $\$ 571.20$ & $\$ 344.33$ & $\$ 572.62$ & $\$ 455.05$ \\
Cost of solar installation after tax credit & & $\$ 9374.89$ & 16.37 & 20.60 \\
Payback Period (years) & & 27.23 & $-\$ 875.21$ & $-\$ 2620.36$ \\
Net present Value at discount rate of $4.49 \%$ & $-\$ 896.29$ & $-\$ 4263.83$ & $-\$ 3819.11$ \\
Net present Value at discount rate of 6.49\% & $-\$ 2401.01$ & $-\$ 5170.91$ & $-\$ 2383.67$ & $-\$ 38 \%$ \\
Internal rate of return & $3.54 \%$ & $-0.65 \%$ & $3.56 \%$ & $1.55 \%$ \\
\hline
\end{tabular}


Table 1 makes it obvious that it is not financially beneficial for homeowners to install solar panels with a $100 \%$ usage offset under the joint IOU proposed rules. Though the use of solar panels reduces the annual electricity charges for the customer, the NPV is negative under all load profiles.

\subsection{Determining the Ideal Usage Offset for Solar Panels under the Joint IOU Proposal}

In our discussion of the Joint IOU proposal for NEM 3.0 we suggested that the proposal was designed to discourage the export of excess energy to the grid. Considering this, we attempted to determine whether smaller solar panel arrays would make more financial sense compared to solar panels sized at $100 \%$ usage offset (as in Table 1). To be more precise, we went about determining the ideal usage offset (the percentage of the home's electricity usage that is provided by solar panels) which would maximize the NPV and the IRR for the installation.

To calculate the payback period, NPV and IRR of solar panel arrays of various sizes, we had to first estimate a model to determine solar panel array pricing. We gathered several recent quotations for residential solar panel installations from reputable local installers, and used those data to arrive at the following pricing model:

Installed cost of solar array $=\$ 4000+\$ 1909 \times$ array size (in $\mathrm{kW} \mathrm{DC)}$

Thus, a $4.541 \mathrm{~kW}$ DC array would cost $\$ 12,668.80$ before federal tax credit, and $\$ 9374.89$ after the federal tax credit (currently at 26\%). Solar panel installations vary greatly in price, not only based on the location and array size, but also based on the roof type and pitch angle, whether the installation is on a flat roof, whether all the panels will be on one roof plane or spread over multiple planes, whether the panels will be on the $1^{\text {st }}$ floor roof or higher, etc. Despite this, the model we have estimated should suffice for this analysis.

We calculated the annual electricity charges, avoided costs, cost of installation, NPV and IRR for various usage offsets in 5\% increments (thus 100\%, 95\%, 90\%, $85 \%$ etc.). A $70 \%$ usage offset would correspond to a solar panel array that produces $70 \%$ of the home's annual electricity consumption. Panels I and II of Table 2 provide the usage offset that results in the maximum NPV for each of the four load profiles assuming a cost of financing of $4.49 \%$ and $6.49 \%$, respectively. Panel III provides the usage offset for each load profile that maximizes IRR.

Table 2 indicates that for load profile B solar panels are a poor investment even when sized optimally at only a $20 \%$ load offset. Although NPV is positive at a low financing cost of $4.49 \%$, the NPV is a meager $\$ 52.21$. For load profile D the ideally sized solar array produces a small positive NPV of $\$ 417.22$ at our lowest assumed discount rate of $4.49 \%$, but a negative NPV at $6.49 \%$. For load profiles $\mathrm{A}$ and $\mathrm{C}$ (the two load profiles where people are home during the peak sunlight hours) the ideally sized solar panel array generates $40 \%$ or $45 \%$ of the home's annual electricity usage, depending on the discount rate. But the NPVs are small, ranging from $\$ 222.74$ to $\$ 1666.35$, which most homeowners will find insufficient 
Table 2. Ideal Usage Offset for Solar Panels under proposed NEM 3.0 rules.

\begin{tabular}{ccccc}
\hline & \multicolumn{4}{c}{ Load Profiles } \\
\cline { 2 - 5 } & A & B & C & D \\
\hline Panel I: Discount rate $=4.49 \%$ & & $20 \%$ & $45 \%$ & $30 \%$ \\
Usage Offset & $45 \%$ & $\$ 52.21$ & $\$ 1666.35$ & $\$ 417.22$ \\
Net Present Value & $\$ 1491.94$ & & & \\
Panel II: Discount rate $=6.49 \%$ & & $20 \%$ & $40 \%$ & $25 \%$ \\
Usage Offset & $40 \%$ & $-\$ 710.07$ & $\$ 333.77$ & $-\$ 516.66$ \\
Net Present Value & $\$ 222.74$ & & & \\
Panel III: Maximum IRR & & $20 \%$ & $40 \%$ & $30 \%$ \\
Usage Offset & $40 \%$ & $4.61 \%$ & $7.13 \%$ & $5.30 \%$ \\
\hline IRR & $6.92 \%$ & & & \\
\hline
\end{tabular}

to justify a solar installation. Compare these NPVs with the numbers reported by Nyer, Broughton, \& Ybarra (2019) of approximately $\$ 16,000$ (for an NEM 1.0 installation of comparable size), or Nyer, Ybarra, \& Broughton (2019) of approximately $\$ 6000$ (for a NEM 2.0 installation of comparable size.) The bottom-line conclusion is that most homeowners will find going solar under the proposed NEM 3.0 rules to be financially unattractive.

\subsection{Financial Impact of Solar Panels and Battery Storage under the Joint IOU Proposal}

As we discussed earlier, the Joint IOU proposal is designed to encourage the installation of battery storage coupled with solar panels. In this section we examine the financial impact of installing solar panels and battery storage. As we did for solar panels, we estimated a model to price battery storage. We obtained several quotations from reputable, local installers for several brands of battery storage systems of various capacities. We arrived at the following model:

Battery Storage Installed Price $=\$ 4500+\$ 473.12 \times$ Usable Battery Capacity (in kW)

Thus, a battery storage system with $9.3 \mathrm{~kW}$ of usable capacity (corresponding to the LG Chem RESU10H system) would cost $\$ 8900$ before federal tax credits, and $\$ 6586$ after the tax credits ( $26 \%$ currently). While there is substantial variability in the price of batteries from one installer to the next, the above model will be adequate for our analyses.

In section 5.2 we established that the customer maximized his NPV and IRR at offset levels substantially lower than $100 \%$. Therefore, to determine the financial impact of installing both solar panels and batteries, we chose to analyze many scenarios where we simultaneously varied both the solar panel array size as well as the battery storage capacity. We used the LG Chem RESU10H as our baseline battery model and then scaled its capacity and price in $10 \%$ increments in both directions (100\%, $90 \%, 110 \%$ etc.) ) until we were able to find the solar panel array size and battery size combination that maximized NPV and IRR for 
each load profile.

Even the best storage batteries available currently have a short performance warranty. As an example, the LG battery is warrantied to retain at least $60 \%$ of its usable capacity of $9.3 \mathrm{~kW}$ for either 10 years or until an energy throughput of 22.4 MWh has occurred. If this battery is charged fully and discharged completely every day, then in the first year of use the battery would have experienced an energy throughput of $3395 \mathrm{kWh}(9.3 \times 365)$. At this rate the battery would reach its warrantied throughput limit in 6.6 years $(22,400 / 3395)$. Thus, in many scenarios, the warranty period will be less than 10 years. To account for this, we kept track of the energy throughput, and reduced the battery's capacity linearly from $100 \%$ to $60 \%$ over the warrantied life. We estimated that the actual end-oflife happened when the battery was twice as old as its warrantied life, and for the years past the warrantied life, the battery's capacity was reduced linearly from $60 \%$ to $0 \%$. After the battery reached end-of-life, the solar panel array would continue to operate until the end of it's warrantied life in year 25 .

Table 3 summarizes the ideal usage offset level for solar panels, and the ideal battery size for each load profile for each of the two assumed discount rates. The corresponding NPVs and IRRs are also shown. Comparing Tables II and III, we see that adding battery storage causes the IRRs for two load profiles to increase (profiles B \& D) while two profiles experience a reduction in IRR (profiles A \& C). Examining Figure I we see that profiles $\mathrm{A}$ and $\mathrm{C}$ are the ones with substantial daytime energy usage (people working from home) where a substantial percentage of the energy produced by the solar panels is used right away without the need for storage. Three of the four NPVs in Table 3 decline compared to Table 2 for profiles $\mathrm{A}$ and $\mathrm{C}$, suggesting that for homes with these load profiles adding battery storage does not make financial sense. From Figure I we see that homes with load profile B (and profile D which while not included in Figure 1 has a

Table 3. Financial Impact of Solar Panels and Battery Storage under proposed NEM 3.0 rules.

\begin{tabular}{ccccc}
\hline \multirow{2}{*}{ Discount Rate $=4.49 \%$} & \multicolumn{4}{c}{ Load Profiles } \\
\cline { 2 - 5 } & A & B & C & D \\
\hline Ideal Usage Offset of Solar Panels & $80 \%$ & $60 \%$ & $65 \%$ & $60 \%$ \\
Ideal Usable Battery Capacity $(\mathrm{kW})$ & $13.95 \mathrm{~kW}$ & $13.02 \mathrm{~kW}$ & $9.30 \mathrm{~kW}$ & $11.16 \mathrm{~kW}$ \\
Net Present Value & $\$ 1549.48$ & $\$ 1729.39$ & $-\$ 32.15$ & $\$ 1552.08$ \\
IRR & $5.45 \%$ & $5.62 \%$ & $4.47 \%$ & $5.56 \%$ \\
\hline Discount Rate $=6.49 \%$ & & Load Profiles & \\
\cline { 2 - 5 } & $\mathbf{A}$ & $\mathbf{B}$ & $\mathbf{C}$ & $\mathrm{D}$ \\
\hline Ideal Usage Offset of Solar Panels & $75 \%$ & $55 \%$ & $55 \%$ & $55 \%$ \\
Ideal Usable Battery Capacity (kW) & $11.16 \mathrm{~kW}$ & $11.16 \mathrm{~kW}$ & $4.65 \mathrm{~kW}$ & $9.30 \mathrm{~kW}$ \\
Net Present Value & $-\$ 1289.72$ & $-\$ 1090.79$ & $-\$ 2182.25$ & $-\$ 1111.39$ \\
IRR & $5.45 \%$ & $5.61 \%$ & $4.17 \%$ & $5.54 \%$ \\
\hline
\end{tabular}


similar pattern as load profile B) use very little energy during the peak sunlight hours, but instead use a lot of energy in the evening. These homes may benefit from using battery storage, though as Table 3 indicates, even under these bestcase scenarios, the NPV is positive only for discount rates below $4.61 \%$ (profile B) and 5.3\% (profile D). Thus most homeowners are unlikely to find solar and battery storage an attractive investment. An important thing to add is that homeowners and installers are unlikely to have the information and the knowledge to design systems that optimize the usage offset size of the solar array, and the battery size based on the load profile of each customer. Thus, the NPVs and IRRs in real-life are likely to be lower.

\subsection{Will a Lower Depth of Discharge Improve the Financials?}

A battery is said to undergo $100 \%$ depth of discharge (DoD) when it is charged to its full capacity and then discharged completely. As we discussed earlier, fully charging and discharging batteries will shorten the warrantied life since the throughput limits will be reached earlier. We examined if lowering the DoD to $80 \%$ will improve the financials. While lowering the DoD helped extend the life of the battery, it did not improve the financials for any of the load profiles. In the interest of brevity, we are not reporting the details here.

\section{Does Going Off-Grid Make Sense?}

California has among the lowest electricity usage per household, but among the highest electricity rates (see Ybarra, Broughton, and Nyer, 2021 for details), and these trends are likely to continue. This is encouraging more California homeowners to go solar. Yet, the Joint IOU proposal, with its strict and limited net metering program and large additional monthly fees, will cause many homeowners to consider whether they would be better off going completely off-grid for their electricity needs. In this section we will estimate the financial implications for the average customer going off-grid.

When going off-grid, the solar and battery system should be sized to not only provide and store the electricity demand for a full day, but also for a few additional days in case there are a few cloudy days in a row. We assume that the customer is unwilling to compromise on his electricity usage.

\subsection{Data}

It is important to understand that by going completely off-grid, the homeowner will be avoiding the annual electricity charges which, as the first row in Table 1 indicates, are about $\$ 2251.10$ (the maximum across all load profiles) for this average home. At a discount rate of 5\%, the NPV of this avoided cost for 25 years (the warrantied life of solar panels) is approximately $\$ 30,216$. If we assume that electricity rates will increase by $3 \%$ each year, then the NPV of this avoided electricity cost increases to $\$ 40,917$. This establishes the upper limit for the cost of the solar plus battery system that the homeowner can install and make the in- 
vestment financially worthwhile. As before, we used data from PVWatts and SCE to calculate the solar generation and the energy use of the average home (discussed earlier) that consumes $7411 \mathrm{kWh}$ of electrical energy each year. We designed a solar panel array that when installed facing due south at a roof tilt angle of 20 degrees would produce exactly $7411 \mathrm{kWh}$ annually (for a usage offset of $100 \%$.) We then calculated the number of days when there would be a shortfall in energy generated by the solar panels, and what the shortfall would be for varying periods ranging from one day to 21 days. What this means is that for every day of the year we calculated the shortfall (if any) for that day, the combined shortfall (if any) for that day and the previous day, the combined shortfall for that day and the previous two days, and so on until we calculated the deficit for 21 days. The maximum of these 21 numbers (which we refer to as maximum energy deficit) was established for each day of the year. We then scaled the solar panel array size upwards in multiples of $20 \%$ (usage offset 100\%, 120\%, 140\% etc.) while noting the shortfall data mentioned previously. The amount of energy to be supplied by the battery was computed for each day of the year by adding the day's energy demand and the maximum energy deficit for that day.

\subsection{Findings}

Table 4 indicates that as the solar panel array size increases (represented by the solar usage offset), the number of days with energy deficit and the battery storage needed decrease. At a usage offset of $220 \%$ the battery storage needed to service the home for the $10-12$ year life of the battery required a capacity of 84 $\mathrm{kWh}$. This accounts for the $95 \%$ round trip efficiency of typical batteries and the degradation in the capacity over the $10-12$ year life of the battery. Even with bulk discounts, the installed cost of such an off-grid system (solar panels and battery storage) is expected to be upwards of $\$ 54,000$ after the federal tax credit. This is more than the NPV of the avoided electricity costs which we established in the previous section. The $\$ 54,000$ initial cost of going off-grid does not include the recurring expenditure of replacing the batteries every $10-12$ years (battery management systems cannot work with combinations of old and new batteries.)

If the homeowner is willing to use a small, inexpensive gasoline generator to charge the battery when the battery is close to being depleted then the system can function with a smaller battery. Table 4 (last column) shows that as the solar panel array size increases the number of days in the year when the battery needs be charged with a gasoline generator decreases. We assume that on any day when the battery is expected to have a shortfall of $8 \mathrm{kWh}$ (or more), the battery will be charged with $16 \mathrm{kWh}$ of energy using a gasoline generator. For a solar panel array sized at $220 \%$ usage offset, the homeowner will have to charge the battery using a gasoline generator on six days in a year (running a $2 \mathrm{~kW}$ gasoline generator for approximately 8 hours on each of these six days.) If this is done, the battery size needed to adequately service the home for $10-12$ years becomes 
Table 4. Going off-grid with and without a supplemental gasoline generator.

\begin{tabular}{ccccc}
\hline & $\begin{array}{c}\text { Number of days } \\
\text { when solar } \\
\text { panels produce } \\
\text { less than the } \\
\text { energy used }\end{array}$ & $\begin{array}{c}\text { Maximum } \\
\text { consecutive days } \\
\text { with energy deficit } \\
\text { from solar panels }\end{array}$ & $\begin{array}{c}\text { Battery capacity } \\
\text { needed for 10 - 12 } \\
\text { year life without } \\
\text { using gas } \\
\text { generator in kWh }\end{array}$ & $\begin{array}{c}\text { Number of days } \\
\text { when gasoline } \\
\text { generator is } \\
\text { needed (towards } \\
\text { end of battery life) }\end{array}$ \\
\hline $120 \%$ & 111 & 9 & 180 & 46 \\
$140 \%$ & 55 & 5 & 133 & 22 \\
$160 \%$ & 47 & 4 & 120 & 18 \\
$180 \%$ & 39 & 4 & 106 & 15 \\
$200 \%$ & 29 & 3 & 92 & 11 \\
$220 \%$ & 26 & 3 & 84 & 6 \\
$240 \%$ & 23 & 3 & 83 & 5 \\
$260 \%$ & 19 & 2 & 82 & 4 \\
$280 \%$ & 15 & 2 & 81 & 3 \\
$300 \%$ & 14 & 2 & 79 & 3 \\
\hline
\end{tabular}

$62 \mathrm{kWh}$ (after accounting for the 95\% round trip efficiency, and the degradation in battery capacity over time) down from the $84 \mathrm{kWh}$ capacity needed with no gasoline generator use. Such a system would cost about $\$ 41,000$ (after federal tax credit) which is still more than the NPV of the avoided electricity charges. Once again this is only the upfront cost and does not include the recurring cost of replacing batteries every 10 - 12 years.

Thus, going off-grid is not a financially viable option for customers who can connect to the grid and who do not wish to cut back on their electricity usage.

\section{Conclusion}

The Joint IOU proposal may very well be a negotiation strategy on the part of the IOUs where they ask for a lot so that they can get some of what they ask for. However, if the CPUC were to adopt all the Joint IOU proposals then residential solar and battery installations in the state are likely to become economically unviable to the homeowners. Under these regulations, even with optimally sized systems, the NPV and IRR from having solar panels alone, or solar panels and battery storage, will be such that most homeowners will not give these investments a second thought. This is precisely what the IOUs want since distributed generation (which includes residential rooftop solar panels) lessens the dependence that customers have on the IOUs and threatens the bottom line of the IOUs. Adoption of the Joint IOU proposal would jeopardize the state's ambitious plans to achieve a statewide goal of carbon neutrality no later than 2045 (California Executive Order, 2018).

\section{Limitations and Future Research}

The analyses done in this paper look at the financial implications of installing 
solar panels and battery storage under the Joint IOU proposal for NEM 3.0. The CPUC may not adopt all or any of the proposed rules or may adopt them with modifications. Follow-up research will have to be done once the NEM 3.0 regulations are finalized. In this paper we examine the financial implications of NEM 3.0 from the perspective of a customer of one IOU-SCE. Perhaps future research could examine the financials for customers of PG\&E and SDGE. While the pricing models we have used to price solar panels and battery storage are robust, the prices for these are falling, and so future research could incorporate updated pricing models.

\section{Conflicts of Interest}

The authors declare no conflicts of interest regarding the publication of this paper.

\section{References}

Broughton, J. B., Nyer, P. U., \& Ybarra, C. E. (2021). The Economics of Battery Storage for Residential Solar Customers in Southern California. American Journal of Industrial and Business Management, 11, 924-932. https://doi.org/10.4236/ajibm.2021.118056

California Executive Order (2018). B-55-18 to Achieve Carbon Neutrality. https://www.ca.gov/archive/gov39/wp-content/uploads/2018/09/9.10.18-Executive-Ord er.pdf

California Public Utilities Commission (2021). Joint Proposal of IOUs. https://docs.cpuc.ca.gov/PublishedDocs/Efile/G000/M371/K711/371711892.PDF

Nyer, P. U., Broughton, J. B., \& Ybarra, C. E. (2019). The Economics of Residential Solar Panel Installations for Customers on Tiered Rate Plans. Open Journal of Business and Management, 7, 1999-2008. https://doi.org/10.4236/ojbm.2019.74137

Nyer, P. U., Ybarra, C. E., \& Broughton, J. B. (2019). The Economics of Residential Solar Panels: Comparing Tiered and Time of Use Plans. Open Journal of Business and Management, 8, 56-67. https://doi.org/10.4236/ojbm.2020.81004

Southern California Edison, SCE (2021a). Energy Data-Reports and Compliance. https://www.sce.com/regulatory/energy-data---reports-and-compliances

Southern California Edison, SCE (2021b). Historical Prices and Rate Schedules. https://www.sce.com/regulatory/tariff-books/historical-rates

Ybarra, C. E., Broughton, J. B., \& Nyer, P. U. (2021). Trends in the Installation of Residential Solar Panels in California. Low Carbon Economy, 12, 63-72.

https://doi.org/10.4236/lce.2021.122004 